\title{
Guerra-Peixe: arranjador de orquestras de rádio
}

\author{
Bruno Renato Lacerda (Universidade Estadual Paulista, São Paulo, SP) \\ bralc@hotmail.com
}

Resumo: Revisão biográfica sobre o músico brasileiro Guerra-Peixe e sua carreira como arranjador de orquestras de rádio. Objetiva-se compreender como compositores clássicos, como Guerra-Peixe, encontraram na esfera popular um meio de vida. Inclui dados biográficos pouco conhecidos sobre o compositor.

Palavras-chave: Guerra-Peixe; música popular brasileira; orquestra de rádio, arranjo.

\section{Guerra-Peixe: an arranger of radio orchestras}

Abstract: Review of literature about Brazilian musician Guerra-Peixe and his career as an arranger of radio orchestras. It aims at understanding how classical composers such as Guerra-Peixe found in the popular sphere a way of living. It also presents some lesser known biographical data on the composer.

Keywords: Guerra-Peixe; Brazilian popular music; radio orchestra; arrangement.

\section{1 - Introdução}

Essa recuperação da trajetória de Guerra-Peixe como arranjador de orquestras de rádio traça em linhas gerais a atuação musical dele no período de vigência dessas orquestras e corresponde à contextualização do estudo analítico de seus arranjos realizada pelo presente autor em sua dissertação de mestrado intitulada Arranjos de Guerra-Peixe para a orquestra da Rádio Nacional do Rio de Janeiro.

César Guerra-Peixe nasceu na cidade de Petrópolis, estado do Rio de Janeiro, em 18 de março de 1914. Filho de pais portugueses recém-chegados ao Brasil, Guerra-Peixe teve nove irmãos, sendo que um deles nasceu no navio durante a viagem a caminho do Brasil. Segundo o depoimento prestado pelo próprio GUERRA-PEIXE (1992b), o sobrenome Peixe se deve ao fato de seu avô ter sido um pescador. Sua familia foi a primeira com esse sobrenome no Brasil.

Guerra-Peixe aprendeu violão e bandolim por meio do incentivo e das instruções recebidas de seu pai e, aos oito anos de idade, em 1922, já integrava o grupo de choro chamado Choro de Carvalho do botequim de portugueses.
Ainda segundo o mesmo depoimento, o grupo era formado pelos seguintes instrumentos: bandolim (GuerraPeixe), trombone, clarinete, contrabaixo (rabecão), violão, surdo e outros instrumentos de percussão (GUERRA-PEI$X E_{1}$ 1992b).

Aos 11 anos de idade, ingressou no curso de violino da Escola de Música Santa Cecília, na qual teve aulas com o professor de violino Gaó Omicht. Nesse curso, GuerraPeixe, de acordo com o seu depoimento, obteve avanço acima da média que resultou em prêmios e, posteriormente, na posição de professor auxiliar de violino (GUERRA-PEIXE, 1992b).

Em 1928, aos 14 anos de idade, ingressou como segundo violino da Orquestra do Cine Glória de Petrópolis (cinema mudo), emprego que the rendia o salário de seis mil réis por dia, 180 por mês, segundo ele, "mais do que muito pai de familia recebia na época" (GUERRA-PEIXE, 1992b). Aos 16 anos de idade, compôs uma peça para piano, um tango intitulado Otilia, em homenagem à sua namorada. Seu pai apresentou a peça para o maestro da banda de Petrópolis, Firmino Borragio, que escreveu um arran- 
jo para ser tocado em uma das sessões do Cine Glória. Guerra-Peixe estudou a partitura desse arranjo e decidiu, a partir dali, compor as próximas peças já com instrumentação apropriada para os grupos disponíveis, mas sempre contando com os conselhos e a ajuda de Firmino Borragio. A partir desse momento, segundo o seu depoimento, GUERRA-PEIXE (1992b) passou a ter seu interesse despertado para o lado da criação musical. Nesse sentido, suas diversas leituras de partituras adquiriram uma nova perspectiva: a da compreensão da escrita musical enquanto criação.

Em 1932, aos 18 anos de idade, entrou no Instituto $\mathrm{Na-}$ cional de Música do Rio de Janeiro e por dois anos ia duas vezes por semana de Petrópolis ao Rio de Janeiro para ter aulas de violino com "Paulina D'Ambrósio, harmonia com Arnaud Gouveia e conjunto de câmara com Orlado Frederico" (NEPOMUCENO, 2001, p.18).

Segundo o artigo escrito por AGUIAR (2007, p.130-131) no livro Guerra-Peixe: um músico brasileiro, em 1934, o compositor concluiu o curso de violino do Instituto $\mathrm{Na}$ cional de Música do Rio de Janeiro e passou a residir nesta cidade definitivamente. Começou a trabalhar como violinista substituto em restaurantes, bailes e gafieiras e, após três meses substituindo o violinista da Taberna da Glória, conseguiu emprego fixo neste lugar, sendo logo transferido para a Orquestra da Casa Belas Artes, emprego que manteve até 1938 quando foi dispensado juntamente com toda a orquestra.

Também segundo AGUIAR (2007, p.131), durante o período em que trabalhou como violinista da Orquestra da Casa Belas Artes, Guerra-Peixe foi apresentado a Radamés Gnattali pelo pianista da mesma orquestra, seu vizinho do bairro do Andaraí: Newton Pinheiro. Os dois, durante as folgas do café-concerto, passaram a fazer frequentes visitas à Rádio Nacional do Rio de Janeiro. Nas primeiras visitas, Guerra-Peixe apresentou seus arranjos a Gnattali na busca de críticas e sugestões e, depois, Gnattali, ao conhecer a escrita de Guerra-Peixe, estendeu-lhe o convite para escrever arranjos "para a famosa Orquestra de Serenata (dois violinos, flauta, clarinete, violoncelo, piano, contrabaixo e bateria)", orquestra responsável por executar música ao vivo em programas da Rádio Nacional do Rio de Janeiro. "Em 1937, Radamés foi convidado por Ayres de Andrade, diretor artístico do programa $A$ Voz do Brasil do DPI [Departamento de Imprensa e Propaganda] para participar do suplemento musical. Nesse programa, Radamés executava várias valsas e choros de Guerra-Peixe".

Ainda em 1938, Guerra-Peixe foi convidado pelo compositor e diretor musical da gravadora Odeon Vicente Paiva para trabalhar como arranjador substituto do maestro Rondon nessa gravadora ao lado de Pixinguinha. Vicente Paiva conheceu a trabalho de Guerra-Peixe por meio dos arranjos que ele fazia (muitas vezes de graça) para as músicas de Ronaldo Lupo e Sant-Clair Senna, geralmente, gravados pelos cantores Gastão Formenti, Moacir Boeno Rocha, Aurora Miranda ou, até mesmo, por Francisco Alves. Por exemplo, este último gravou a música Sonhei com teus carinhos, de Sant-Clair Senna e Guerra-Peixe, lançada pelo selo Columbia. GUERRA-PEIXE (1979, p.27) descreve como foi esse período de sua vida:

Comecei a me aprimorar e fazer arranjos para a Aurora Miranda, Francisco Alves, etc. Aliás, o Chico gravou um samba meu na época, meu e do Sant-Clair Sena, chamado Sonhei com Teus Carinhos. Eu sei que dois dos meus arranjos foram parar na Odeon, numa época em que Pixinguinha e o maestro Rondon, que estava doente e não podia orquestrar. Era um trabalho para os dois, mais ainda para um só. Foi quando o Vicente Paiva, na época diretor da gravadora, viu esses dois arranjos e me convidou para trabalhar na gravadora.

Nessa época de sua vida, Guerra-Peixe leu pela primeira vez o livro, de Mário de Andrade, Ensaio sobre a música brasileira e chegou à seguinte constatação: "Foi aí que eu tive a primeira revelação (...) eu nem sabia que existia a tal música brasileira" (FARIA JR., 1997, p.9).

A soma desses fatores - contrato na Odeon, leitura das propostas de Mário de Andrade como estímulo aos compositores brasileiros, o convívio com Radamés Gnattali, um músico que se sustentava com o trabalho de arranjador, o desgosto do trabalho instável de músico da noite e a finalização dos estudos de violino - contribuíram para que Guerra-Peixe tomasse a decisão de procurar um professor para aprofundar os seus estudos musicais. Assim, como citado por FARIA JR. (1997, p.9), Guerra-Peixe declarou: "procurei um professor e encontrei um ótimo em Newton Pádua". Com isso, de 1938 até 1943, GuerraPeixe teve aulas particulares com Newton Pádua aprendendo contraponto, fuga, composição, instrumentação, orquestração e harmonia. Nesse meio tempo, segundo ONOFRE (2005, p.240), entrou no Conservatório Brasileiro de Música, em 1941, sendo o primeiro aluno do estabelecimento e do Brasil a concluir o curso de Instrumentação e Composição, no final do ano de 1943.

Com o progressivo avanço dos estudos, Guerra-Peixe desenvolveu o domínio da técnica de composição musical, o que veio a se somar ao treinamento prático advindo da feitura de arranjos fazendo com que assumisse a carreira e a postura da profissão de arranjador e, logo, a de compositor - "e quando menos esperava virei compositor", citado por FARIA JR. (1997, p.9).

\section{2 - Rio de Janeiro, 1942-1946: o trabalho na Rádio Tupi}

Em 1942, o saxofonista dirigente de orquestras itinerantes Otaviano Romero Monteiro (1908-1951) - o maestro Fom-Fom -, que entrou e saiu só na Rádio Tupi do Rio de Janeiro mais de três vezes, convenceu o diretor superintendente desta emissora, Theóphilo de Barros Filho, a contratar Guerra-Peixe para o cargo de arranjador. Acontece que Fom-Fom, como era conhecido, não possuía suficiente conhecimento para realizar arranjos para orquestra de rádio, o que gerou o argumento de que não sabia 
ler partitura, mas sabia comunicar aos músicos o que queria. Assim, naquele ano se iniciou, formalmente, a carreira de Guerra-Peixe como arranjador de orquestras de rádio. Segundo o depoimento do próprio GUERRA-PEIXE (1992a), esse contrato não o impedia de realizar outros trabalhos, mesmo em outras emissoras, todavia, durante o seu contrato com a Rádio Tupi do Rio de Janeiro ele não fez arranjos para nenhuma orquestra de outra emissora.

Seus primeiros arranjos na Rádio Tupi foram executados contemporaneamente à estreia do programa História do Rio pela música, que teve início no dia 21 de dezembro de 1942, sobre a organização do radialista Almirante. CABRAL $(1990$, p.213, 214) menciona que a orquestra da emissora ainda contava com um coral e que os arranjos de Guerra-Peixe eram regidos pelos maestros Fom-Fom e Milton Calazans.

No dia 4 de maio de 1943, estreou o programa Instantâneos Sinfônicos Schenley, inspirado na estética composicional de George Gershwin. 0 programa tinha um forte cunho político de exaltação americana, sobretudo por causa da presença brasileira na Aliança contra o Eixo. 0 programa, patrocinado pela marca de uisque Schenley, que nunca chegou ao Brasil, contava com um elenco de cem pessoas, tendo como diretores Olavo de Barros e Paulo Porto, redação de Guilherme Figueiredo e direção geral de Theóphilo Barros Filho. Guerra-Peixe ganhava cerca de três contos de réis por programa tendo que escrever arranjos e compor "quase uma hora de música orquestral em dois dias" (AGUIAR, 2007, p.133). Segundo GUERRA-PEIXE (1979, p.1-2) declarou, "o fato é que, durante dois anos, através do programa, tive uma orquestra sinfônica à minha disposição". Vale dizer que, segundo o depoimento de GUERRAPEIXE (1992b), entre os músicos integrantes dessa orquestra estava seu professor Newton Pádua executando ao violoncelo os arranjos que Guerra-Peixe escrevia.

O desenvolvimento de sua técnica composicional ocorreu em paralelo ao aumento de seu prestígio como compositor. 0 envolvimento com o meio profissional das rádios forneceu oportunidades para Guerra-Peixe divulgar sua obra e se tornar conhecido no meio artístico da época. Um exemplo disso foi o convite feito pelo empresário radiofônico Assis Chateaubriand para a apresentação da Sinfonia $n^{\circ} 1$ de Guerra-Peixe na inauguração dos novos aparelhos transmissores da Rádio Tupi, que foi realizada no Teatro Municipal, no dia 9 de julho de 1944, como lembra AGUIAR (2007, p.134).

Guerra-Peixe adotou o nome Fase inicial para designar as composições de 1942 a 1943 e nessa fase incluiu apenas duas obras: a Suite Infantil e o hino patriótico Fibra de herói ${ }^{1}$, também conhecido como Bandeira do Brasil, "com texto de Teófilo de Barros Filho e gravação original de Silvio Caldas" (MIGUEL, 2006, p. 24).

Para o musicólogo FARIA JR. (2000, p.173), a Fase Inicial de Guerra-Peixe corresponde ao período de 1937 a 1944. Nesse período, as composições de Guerra-Peixe apresentam uma estética neoclássica com elementos extraídos da música popular brasileira, por exemplo, o choro. Porém, segundo FARIA JR. (2000, p.173), esses elementos são usados como citação literal, ou seja, os componentes usados nas composições ainda não são criações próprias do compositor.

Nesse sentido, esse processo se assemelha ao trabalho do arranjador que toma, por exemplo, um tema de outro para explorá-lo e desenvolvê-lo como quer. Acredita-se que, também, tenha sido por meio desse processo que Guerra-Peixe passou de arranjador para compositor, 0 que torna ainda mais significativa o papel da sua carreira como arranjador de orquestras de rádio para o desenvolvimento de sua técnica composicional.

Entre março e maio de 1946, "toda quinta-feira, no horário nobre das 21 horas, sob o patrocínio de Phymatosan", Guerra-Peixe escreveu arranjos para o programa chamado Ritmos cruzados transmitido pela Rádio Tupi do Rio de Janeiro (AGUIAR, 2007, p.136). "Nesse programa, por exemplo, Guerra-Peixe brincava com os gêneros e ritmos: apresentava sucessos populares com arranjos eruditos e transportava peças clássicas, como as de Beethoven, para o ritmo de samba" (NEPOMUCENO, 2001, p.24). "Desse modo, Moto perpétuo toma forma de choro, Sonata ao luar de swing, Sobre as ondas e Danúbio azul, sambas. Até $O$ Vira acaba transformado em maracatu" (AGUIAR, 2007, p.136).

Após quatro anos de serviço prestado à emissora da Rádio Tupi do Rio de Janeiro, Guerra-Peixe encerrou definitivamente seu vínculo de arranjador contratado dessa emissora, em maio de 1946. Segundo AGUIAR (2007, p.136), nessa ocasião, a Rádio Nacional do Rio de Janeiro ofereceu a Guerra-Peixe o salário de $\operatorname{Cr} \$ 8.000,00$ mensais ("cerca de quarenta salários mínimos") para trabalhar na função de maestro nessa rádio. Contudo, em junho desse mesmo ano, ele começou a trabalhar na Rádio Globo e, a partir do dia 8 de agosto, passou a apresentar, "no horário nobre das 20 horas, o programa Arranjos orquestrais, de caráter acentuadamente dançante (...), Uma história em cada música, bem como a trilha sonora da radionovela Amor eterno de Nelson Nobre, com direção de Amaral Gurgel".

A opção pela Rádio Globo ao invés da Rádio Nacional do Rio de Janeiro, apesar do maior prestígio e salário oferecidos pela segunda, se deve ao fato de que Guerra-Peixe queria ter tempo para estudar música. Na época, o compositor conversou com Radamés Gnattali, arranjador contratado da Rádio Nacional, e, a partir desse diálogo, percebeu que a emissora exigia muito dos seus profissionais e isso iria interferir em seus planos de estudo. Por isso a escolha pela Rádio Globo, que lhe proporcionou melhores condições para desenvolver os seus estudos musicais, como explicou GUERRA-PEIXE (1992a) em seu depoimento.

Com a dispensa da orquestra da Rádio Globo, no início de 1947, emissora que passou a basear sua programação em esporte, notícias e músicas transmitidas pelo disco, Guer- 
ra-Peixe ficou um período afastado do trabalho de arranjador de orquestras de rádio até ser contratado pela Rádio Nacional do Rio de Janeiro, no dia 15 de abril de 1948.

\section{3 - Rio de Janeiro, 1948-1949: o trabalho na Rádio Nacional do Rio de Janeiro}

Do dia 15 de abril de 1948 a $1^{\circ}$ de agosto de 1949, conforme consta no documento arquivado (ficha funcional) da sede da emissora, Guerra-Peixe teve sua primeira passagem pela Rádio Nacional do Rio de Janeiro. Segundo AGUIAR (2007, p.137), Guerra-Peixe foi efetivado a convite do então diretor Victor Costa para se responsabilizar, entre outras tarefas, pelos arranjos para o programa chamado Dicionário Toddy, produzido por Fernando Lobo.

No contrato de Guerra-Peixe com a Rádio Nacional estão presentes as seguintes informações descritas por PEREIRA (2006, p.71):

0 contrato de Guerra-Peixe, que data de 4 de abril de 1948, é um documento todo datilografado. 0 contrato de número 64 indica 0 cargo de Maestro e apresenta o seguinte, contendo as funções que o funcionário se comprometeu a desempenhar: $1^{\circ} 0$ artista que se contrata como maestro, se obriga a participar dos programas e ensaios, a fazer orquestrações e arranjos para orquestras e coros de música, a atuar como regente de orquestra e colaborar como música executante nos programas da Rádio Nacional.

0 ano de 1949 foi um ano de crise para Guerra-Peixe, pois na época teve que tomar decisões dificeis e de consequências duradouras. Por um lado, Guerra-Peixe fez a crucial escolha do abandono do dodecafonismo e, por outro, teve que escolher entre quatro opções de meio para a sua subsistência. A primeira era aceitar a proposta do regente alemão Hermann Scherchen ${ }^{2}$ que, em breve estada no Rio de Janeiro, fez questão de conhecê-lo e convidá-lo para trabalhar como arranjador em programas de músicas populares e folclóricas, a principio, brasileiras, na Rádio de Zurique na Alemanha, como relatou a musicóloga ASSIS (2007, p.8). Esse emprego, que lhe daria o direito de morar na casa do maestro Hermann Scherchen, envolvia aulas de aperfeiçoamento de regência com Scherchen e a oportunidade de praticar os ensinamentos na Orquestra Sinfônica da Rádio de Zurique, foi um convite recusado.

A segunda opção, de acordo com depoimento do próprio GUERRA-PEIXE (1992b), seria aceitar a proposta do compositor Aaron Copland que, ao vir para o Brasil interessado em encontrar um compositor de até 30 anos a quem dar uma bolsa de estudos nos Estados Unidos, conheceu Guerra-Peixe pessoalmente, mas não pôde lhe dar a bolsa porque Guerra-Peixe já tinha 36 anos na ocasião. Guerra-Peixe mostrou ao compositor americano algumas partituras de suas peças dodecafônicas e Copland, examinando-as, teve sua estima despertada pelo compositor e lhe garantiu um emprego de professor de música em uma das universidades dos Estados Unidos, se ele tão somente aprendesse o idioma inglês. Convite também recusado.
A terceira opção era permanecer no Rio de Janeiro e continuar trabalhando na Rádio Nacional. Porém, possivelmente por motivos pessoais, em seu depoimento, GUERRA-PEIXE (1992b) revela que considerava essa opção inaceitável, pois alegava que tinha que sair dessa cidade de qualquer maneira.

Assim, sua decisão recaiu sobre a quarta opção: conciliar o emprego de arranjador com as pesquisas de música folclórica que forneceria material sonoro para suas composições - seguindo a cartilha de Mário de Andrade.

Em junho de 1949, após tirar um mês de licença na Rádio Nacional, viaja para o Recife, a convite de Teóphilo de Barros Filho [ex-diretor da Rádio Tupi do Rio de Janeiro e atual diretor da Rádio Jornal do Comércio do Recife], para colaborar na comemoração do 1 aniversário da Rádio Jornal do Comércio. Da janela do hotel ouve um pregão de cocada que inspira sua primeira obra nacionalista Suite para cordas [quarteto de cordas ou orquestra de cordas]. (...) Diante de uma proposta para trabalhar na Rádio Jornal do Comércio não titubeia em fixar residência na capital pernambucana. Em 8 de dezembro de1949, casa-se no Rio com a jovem Célia [da Rocha] Pinto [então Célia GuerraPeixe], de quem se separará em 1975. No dia seguinte ao casamento, parte para o Recife, aonde chega em 16 de dezembro, permanecendo naquela cidade por três profícuos anos (AGUIAR, 2007, p.137).

Antes de dar procedimento ao estudo de Guerra-Peixe como arranjador da Rádio Jornal do Comércio de Recife, convém fazer uma observação sobre as atividades paralelas que ele manteve como compositor dodecafônico e arranjador de música popular. Conforme MARIZ (1953, p.11) assinalou em artigo escrito para o jornal Correio da Manhã, "na realidade, custa crer que o Guerra-Peixe arranjador de sambas e baiões tenha escrito, ao mesmo tempo, peças de um cerebralismo atroz". Entretanto, GUERRA-PEIXE (1992a) explica claramente como conciliava as duas atividades, aparentemente, antagônicas:

Eu sempre tive duas atividades. Uma como arranjador e outra como compositor. Eu sempre pensei que não tinha nada a ver uma coisa com a outra. Mas como arranjador eu tive uma experiência muito grande, certa ordem para ver as coisas, por ser uma coisa mais simples. Mesmo quando a gente faz uma coisa mais avançadinha para o público, sempre tem um limite.

Nesse depoimento, Guerra-Peixe se lembrou de uma curiosa situação em que inseriu uma vinheta dodecafônica especialmente composta para esta função em um programa radiofônico. 0 resultado foi o esperado: os técnicos do estúdio tamparam os ouvidos e o diretor veio conversar com ele, e disse algo do tipo: "Olha, Guerra, você tem que escrever algo que agrade ao ouvinte, nós temos que tocar aquilo que a gente sabe que o ouvinte vai gostar". Uma grande mudança no nivel de experimentação em comparação com aquelas vinhetas que ele escrevia e os cantores queriam colocar letra para gravar. 
Outra observação pode ser feita com referência ao período em que recebeu consideráveis propostas para atuar no exterior, pois, nessa época (1922-1945), era de vital importância para a consagração artística passar por uma experiência no exterior, como, por exemplo, aconteceu com o compositor Villa Lobos. Na maioria das vezes, esse era um objetivo almejado por boa parte dos artistas, por servir também como forma de aperfeiçoamento técnico.

Entretanto, Guerra-Peixe sempre acreditou que tudo que um músico precisava aprender poderia ser encontrado no Brasil sem precisar viajar para o exterior. Ele pensava também que a principal lição para o músico brasileiro só poderia ser aprendida no Brasil por meio de pesquisas de campo como as que ele realizou, por exemplo, em Recife, no interior e litoral paulista, e outros músicos e musicólogos realizaram em outros locais do país.

0 fato é que, por diversos motivos já bastante explicados por outros pesquisadores, Guerra-Peixe abandonou definitivamente o dodecafonismo, em 1950, para se dedicar à pesquisa e à composição, segundo o nacionalismo musical proposto por Mário de Andrade.

\section{4 - Recife, 1950-1953: o trabalho na Rádio Jornal do Comércio}

No seu primeiro trabalho para a Rádio Jornal do Comércio de Recife, durante o mês de junho de 1949, Guerra-Peixe compôs a Suite para orquestra de cordas com a intenção de experimentar as danças nacionais. Essa suite apresenta os seguintes movimentos: Maracatu, Pregão, Modinha e Frevo. Vale ressaltar que essa música foi escrita para os músicos dessa rádio, bem como executada e gravada por eles. Guerra-Peixe declarou ao ouvir a gravação: "agrada muito como primeira composição nacionalizante" (ARAÚJO, 2007, p.3).

Nos primeiros contatos de Guerra-Peixe com o Recife e com a Rádio Jornal do Comércio, os músicos da emissora foram se entusiasmando com ele e ele com os músicos. Ele nutriu uma admiração pela riqueza e pela variedade das manifestações culturais do lugar e, por isso, combinou com aqueles músicos que, assim que ele se desligasse da Rádio Nacional do Rio de Janeiro, voltaria para o Recife para trabalhar como maestro da Rádio Jornal do Comércio.

Guerra-Peixe partiu do Rio de Janeiro para Recife no dia 16 de dezembro de 1949 e voltou do Recife para o Rio de Janeiro no dia 27 de novembro de 1952, após três anos de muita pesquisa e de muito trabalho. De fato, segundo ele mesmo declarou sua viagem, não foi a passeio (GUERRAPEIXE, 1979, p.27).

Entre os programas que Guerra-Peixe era responsável por escrever, destacam-se os arranjos para a orquestra da Rádio do Comércio, como Harmonias nitroquímicas, Jardim de melodias (patrocinado pelo Regulador Xavier), Ritmos cruzados, Arranjos orquestrais e Fantasia, este último como trilha para textos de Joel Pontes, de acordo com AGUIAR (2007, p.138).
Nesse período, além de arranjos para programas de rádio, pesquisas e composições, Guerra-Peixe "foi professor de Clóvis Pereira, que de gaitista passou a orquestrador, do famoso mestre Capiba [Lourenço da Fonseca Barbosa]", que teve importante papel como arranjador de músicas apresentadas no Festival Internacional da Canção, na década de 1960, e de Sivuca (Severino Dias de Oliveira), "músico famoso internacionalmente e grande orquestrador", como citado NONNO (1997, p.44).

Vale lembrar que Hermeto Pascoal tocava acordeom no regional da Rádio Jornal do Comércio de Recife no período em que Guerra-Peixe trabalhou como regente e arranjador da orquestra dessa emissora. Nessa época, Pascoal ainda era jovem, mas muito observador, admirava a importância que Guerra-Peixe dava à música local. Podese dizer que o jovem talento teve sua estima despertada para a sua música cotidiana e natal por meio da observação dos intensos estudos etnomusicológicos que GuerraPeixe realizou em Recife. Pascoal também aproveitava as oportunidades para assistir aos ensaios da orquestra realizados por Guerra-Peixe e observava atentamente como o compositor experimentava na orquestra os ritmos folclóricos pesquisados. Pode-se dizer que tal experiência tenha tido viva representatividade nas futuras composições de Pascoal. No entanto, Guerra-Peixe talvez tenha conhecido Hermeto Pascoal apenas como instrumentista. Ou ainda é possível que o futuro compositor Ihe tenha passado despercebido.

Na Rádio do Jornal do Comércio, Guerra-Peixe teve uma nova experiência, pois o compositor explorou na orquestra da emissora os ritmos e gêneros musicais diretamente ligados com as suas pesquisas. Em diversos testemunhos que deu, ele deixou claro o seu entusiasmo em poder transferir para a formação instrumental das orquestras de rádio os diversos ritmos folclóricos das músicas que estava pesquisando, como certa vez noticiou, no dia 23 de fevereiro de 1950, em correspondência a Mozart de Araújo:

\footnotetext{
Maracatu - Já tive a ousadia de escrevê-los numa rapsódia que fiz para um programa de rádio. Digo ousadia porque os músicos pregavam que a orquestra da rádio não tocava níquel do verdadeiro maracatu. Entretanto (...) a trompa tocou direitinho faltando somente um pouco de estilo que é coisa que virá a seu tempo (...) (FARIA JR., 1997, p.42).
}

0 período que permaneceu em Recife foi de grande importância para a ampliação do material sonoro e musical que Guerra-Peixe passou a empregar em suas composições, bem como para a aquisição de informações sobre as manifestações folclóricas que, graças às suas coletas e registro de materiais, forneceram subsídios para a compreensão de tais manifestações por parte de diversos músicos e musicólogos interessados no assunto.

Naquela época, Guerra-Peixe simplificou a sua escrita composicional em uma clara oposição à estética dodecafônica praticada anteriormente. Tal fato também pode ser atribuído ao seu vínculo com a prática de arranjo para música popular que, por sua vez, visa essencialmente à 
simplicidade como recurso para uma comunicação mais direta com o público. Além disso, a visão política advinda do seu pensamento partidário do realismo socialista - comunismo - também explica seu objetivo de compor músicas com maior facilidade de assimilação.

Talvez, Guerra-Peixe poderia ter permanecido mais tempo no Recife, porém, segundo AGUIAR (2007, p.140), o seu nome foi associado às ideias progressistas do movimento de esquerda em uma época em que isso gerava uma série de complicações pessoais, como as que foram geradas para Guerra-Peixe: intrigas "promovidas por intelectuais reacionários do Recife envolvendo o seu nome".

Com intenção de evitar maiores problemas, GuerraPeixe voltou para o Rio de Janeiro, em 27 de novembro de 1952, onde permaneceu até se mudar para São Paulo, no início de 1953.

Com a mudança para São Paulo, segundo o musicólogo FARIA JR. (1997, p.35), Guerra-Peixe pretendia dar continuidade ao seu trabalho como compositor de trilhas sonoras para companhia cinematografia Vera Cruz, cumprir contrato com a emissora Rádio Nacional de São Paulo e prosseguir com as pesquisas folclóricas, agora nas cidades do interior e do litoral paulista.

Segundo a divisão estabelecida pelo próprio GUERRAPEIXE (1992a), suas fases estéticas podem ser divididas da seguinte maneira: Fase inicial, de 1943 a 1944, Primeira fase (dodecafônica), de 1944 a 1950 e Segunda fase, de 1950 a 1960, ou seja, a Segunda fase abrange o período em que morou em São Paulo.

\section{5 - São Paulo, 1953-1961: o trabalho na Rá- dio Nacional de São Paulo}

No dia $1^{\circ}$ de maio de 1952, o ex-diretor da Rádio Nacional do Rio de Janeiro Victor Costa chegou a São Paulo com autorização do governo federal, em nome de Getúlio Vargas, para comprar as instalações, o prefixo e a frequência da Rádio Excelsior, a fim de instalar em seu lugar Rádio Nacional de São Paulo. Ao fazer isso, de acordo com o radialista TAVARES (1999, p.70), Victor Costa rompeu com um acordo tácito entre os proprietários das Emissoras Associadas de São Paulo que impedia a transferência de prefixos entre emissoras radiofônicas. Com isso, a frequência e o prefixo da Rádio Transmissora passaram a sintonizar a Rádio Nacional de São Paulo que, posteriormente, se tornou Rádio Globo, e a Rádio Transmissora adquiriu novo prefixo e nova frequência tornando-se a Central Brasileira de Notícias - CBN.

A primeira providência das Organizações Victor Costa foi contratar os melhores profissionais das Empresas Associadas, inclusive o seu diretor e chefe Derminal Costa Lima. A partir da orientação de Victor Costa, a Rádio Nacional de São Paulo passou a formar um elenco com os principais nomes das diversas áreas de atuação da radiofonia paulista, sendo poucos os que não aceitaram as propostas financei- ramente recompensadoras dessa organização. Desse modo, de acordo com a pesquisa de PIRES (2000, p.202), enquanto houve um desfalque no corpo de profissionais das outras emissoras paulistas, ocorreu, ao mesmo tempo, um rápido crescimento da Rádio Nacional de São Paulo.

No setor musical o elenco foi formado por uma orquestra de 45 instrumentistas que recebia arranjos e regência de maestros como Gaó (Odmar Amaral Gurgel), Spartaco Rossi, Osmar Milani, Alberto Lazzoli, Oliver de Sousa, além de Guerra-Peixe, segundo as informações de PIRES (2000, p.198).

Segundo AGUIAR (2007, p141), no mesmo mês da inauguração Guerra-Peixe já estava incumbido de produzir arranjos para o programa Ritmos e melodias Arno. Neste programa, o repertório era mais voltado para a música popular urbana paulista, mas sempre que possivel Guerra-Peixe incluia gêneros pernambucanos como o frevo. Tal programa mudou de patrocinador duas vezes, passou, em 1955, para a empresa Ovomaltine, tornando-se Ritmo e melodias Ovomaltine e, logo depois, para o Ritmo e melodias brasilianas.

A TV Paulista também estava sob a direção das Organizações Victor Costa. Essa emissora de televisão contava com o elenco de artistas de rádio para atuar nos seus programas, e algumas transmissões ocorriam simultaneamente nos dois veículos. Vale lembrar que naquela época a base para a realização de programas televisivos vinha da rádio. Entre algumas das participações de Guerra-Peixe nesses programas, AGUIAR (2007, p.142) lembra que:

Em 1956 passa a trabalhar na TV Paulista, criando os prefixos musicais para as Organizações Victor Costa. Juntamente com outros regentes participa do programa Quando os Maestros se Encontram, transmitido simultaneamente pela Rádio Nacional, espécie de desafio entre os arranjadores, que permanece no ar até 1960. No mesmo ano, aperfeiçoa-se como regente tendo aulas com o maestro Eduardo Di Guarnieri. Em 1957, na Rádio Nacional produz os programas Um milhão de Ritmos, Festa de Ritmos e Grande Espetáculo, este último transmitido em conjunto com a TV Paulista. No mesmo ano, participa, ainda na TV Paulista, dos Recitais Cosmopolitas, onde faz a estreia de $A$ Inúbia do Cabocolinho. No ano seguinte, apresenta pela Rádio Nacional os programas Cancioneiro Armour e o curioso Desconversando em que analisa os últimos lançamentos fonográficos.

Aparentemente foi através desse último programa que se tornou conhecida a crítica positiva de Guerra-Peixe em favor da bossa nova. Nesse sentido, o jornalista CASTRO (1999, p.242-243) menciona que:

Com algumas exceções, como Gabriel Migliori e Oswaldo Borba, os demais maestros - Peracchi, Panicalli, Radamés e, claro, Lindolfo Gaya e Moacir Santos - apoiaram ou aderiram abertamente à nova música. Os maestros jovens de São Paulo, como Rogério Duprat, Diogo Pacheco e Júlio Medaglia, estes se apaixonaram em bloco, talvez porque, como Jobim e Severino Filho, dois cariocas, tivessem sido alunos do alemão radicado no Rio: Hans Joachim Koellreutter. E outro maestro, Guerra-Peixe, ex-professor de [Roberto] Menescal, só faltou vestir a casaca para dar a sua opinião: "A bossa nova é uma inseticida sonora na aspereza batuqueira e na castração bolerosa". 
Inclusive, foi com a interpretação do hino Fibra de herói que João Gilberto convenceu Oswaldo Gurzoni, um dos donos da rede de lojas de discos Assumpção, a colocar o LP Chega de saudade à venda - "por toda São Paulo, o disco foi recordista de vendas dessa loja, aquele ano" (CASTRO, 1999, p.188). A ligação entre Guerra-Peixe e João Gilberto não parou aí, pois sempre que o segundo precisava de uma palavra final sobre alguma produção era a Guerra-Peixe que recorria e, ao receber a aprovação do compositor, efetuava a gravação com mais segurança.

Esses fatos se devem a uma vida na capital paulista "marcada pelo respeito e credibilidade", pois foi reconhecido como "um grande profissional do rádio, do cinema, da pesquisa folclórica e das salas de concerto", tudo como resultado de sua dedicação à música "sem fronteiras" (AGUIAR, 2007, p.141), reconhecimento este que lhe proporcionou prêmios nas diversas áreas em que atuou.

Neste periodo, Guerra-Peixe recebeu seis vezes os troféus Roquete Pinto e Tupi mirim referentes ao melhor funcionário do ano, oferecido pela AFEU - Associação dos Funcionários das Emissoras Unidas e Associadas de São Paulo.

No período em que morou em São Paulo, Guerra-Peixe recebeu uma média de seis convites por ano para viajar para o exterior, "além de uma bolsa oferecida pela UNESCO [Organização das Nações Unidas para a Educação, a Ciência e a Cultura] por dois anos, para divulgação das suas obras em Paris". Nesse episódio, "houve a tentativa da parte do compositor de permuta (...), em vez de Paris, o compositor gostaria de ter ido para Angola, onde poderia desenvolver outras pesquisas; no entanto, a resposta foi negativa" (DELL'ORTO, 1998, p.6). Pelo que se sabe Guerra-Peixe nunca viajou para fora do Brasil, porém seu nome e sua música percorreram e ainda percorrem o mundo todo.

Nesse período de sua vida, segundo entrevista concedida pelo compositor (1971, p.4), ocorreram outros fatos importantes referente à sua relação com o rádio, por exemplo: a execução de sua Sinfonia $n^{\circ} 2$ Brasília na Rádio do Ministério da Educação e Cultura do Rio de Janeiro por ocasião de um concurso de composição, em 1960, no qual ficou em segundo lugar junto com Cláudio Santoro e Guerra Vicente (não houve primeiro lugar). Houve também a realização de um recital sob sua direção e regência na demonstração de música popular brasileira para congressistas estrangeiros que participavam do Congresso Internacional de Folclore, patrocinado pela Comissão do IV Centenário da cidade de São Paulo, realizado no auditório da Rádio Nacional de São Paulo, em 1954.

Foi também durante sua estada em São Paulo que aconteceram outros fatos relevantes na carreira de Guerra-Peixe, como a nomeação para o cargo de chefe do setor musical da Secretaria da Comissão Paulista de Folclore, a participação nos jornais 0 Tempo e $A$ Gazeta, nos quais tinha colunas semanais em que escrevia artigos sobre folclore musical brasileiro e música popular urbana e a conquista de uma maior maturidade na composição que, segundo citado por MIGUEL (2006, p.39), teve início a partir do Quarteto n² (02/03/1958), "referência para tudo o que vem depois".

De acordo com AGUIAR (2007, p.143), após oito anos passados na capital paulista, Guerra-Peixe teve o seu contrato com a Rádio Nacional de São Paulo vencido e retornou ao Rio de Janeiro, em 27 de março de 1961.

\section{6 - Rio de Janeiro, 1961-1967: o trabalho na Rádio Nacional do Rio de Janeiro}

A segunda contratação pela Rádio Nacional do Rio de Janeiro foi cumprida do dia 2 de outubro de 1961 ao dia $1^{\circ}$ de maio de 1967, conforme consta em documento arquivado (ficha documental) na sede dessa emissora.

Desde a sua volta ao Rio de Janeiro até o momento de sua contratação pela Rádio Nacional, Guerra-Peixe trabalhou como autônomo dando aulas particulares semelhantes às que ele havia dado no período em que viveu em Recife, conforme notou AGUIAR (2007, p.142).

Nota-se que ainda não era possivel, mesmo para um músico de sua formação e experiência, viver como compositor de música clássica no Brasil. A solução para esse impasse era a atuação como arranjador nas orquestras de rádio. 0 fato de Guerra-Peixe retornar ao trabalho de arranjador de orquestras de rádio é exemplo disso. Esse era um trabalho, ainda na década de 1960, estável, com uma remuneração fixa e que tinha ligação com o que um compositor realmente gosta de fazer: escrever e criar música.

Por ocasião da recontratação de Guerra-Peixe pela Rádio Nacional, o radialista Paulo Tapajós estava reivindicando melhorias de salário para os arranjadores. Como forma de argumentação, Tapajós lembrava a direção que:

Lyrio Panicali, José Zimbres, Cid dos Santos e Romeu Fossati estavam sendo transferidos para o serviço público e, com isso, a emissora estaria fazendo uma economia de aproximadamente $\mathrm{Cr}$ 133. 700, 00 , quantia que poderia ser utilizada para reajustar o salário dos maestros que permaneceram na emissora (PEREIRA, 2006, p.56-57).

Acredita-se que parte dessa verba $(\mathrm{Cr} \$ 25.000,00)$ tenha sido destinada à recontratação de Guerra-Peixe que, ao voltar para a emissora naquele momento, também estava suprindo o desfalque ocasionado pela saída desses e de outros maestros, pois, segundo o levantamento de PEREIRA (2006, p.55-57), na década de 1960, foram desligados sete maestros da Rádio Nacional, "sendo a maioria transferida para o serviço público".

Na Tabela de Remuneração e Função dos Maestros da Rádio Nacional do Rio de Janeiro, apresentada pela pesquisa de PEREIRA (2006, p.51), constam os seguintes dados sobre o contrato de Guerra-Peixe.

Os arranjadores da Rádio Nacional do Rio de Janeiro não ocupavam uma função específica indicada apenas pelo cargo de maestro. Assim, não é possivel afirmar se Guerra-Peixe ficava responsável pela elaboração de arranjos exclusivos para um determinado programa da emissora. 
Sabe-se, no entanto, que ele teve seus arranjos executados nos seguintes programas:

\begin{abstract}
Alegria da rua, alma do Brasil, Cancioneiro romântico, Cantando para você, Carrossel musical, Dicionário Toddy, Flash musical, Isto é show, Jornal sem banca, Meio século de canções, No mundo das notas, Paulo Gracindo, Quando os maestros se encontram e Refrescando a memória. Guerra-Peixe também trabalhou na publicidade [vinhetas] (PEREIRA, 2006, p.36-37).
\end{abstract}

Nas partituras com os arranjos de Guerra-Peixe selecionadas e impressas no Museu da Imagem do Som do Rio de Janeiro também constam, entre outros, o nome dos seguintes programas: Paradas de sucessos, 21 anos de Manuel Barcelos, Paulo Gracindo, Cantando para você, Musical romântico, Galeria musical, Três estrelinhas, Meu Rio é assim e Estreia ao meio-dia.

0 nome da função preenchida nas fichas cadastrais, por exemplo, como regente, arranjador, maestro ou orquestrador, significava que esses músicos deveriam estar obrigados a "ensaiar, tocar, gravar, compor, arranjar, reger independentemente do nome de seus cargos, ou seja, tinham que fazer de tudo para manter seus empregos" (PEREIRA, 2006, p.72).

Ainda em trabalhos veiculados no rádio, nos anos de 1964 e 1965, Guerra-Peixe escreveu arranjos especiais para programas da Rádio e TV Globo, tal como Uma canção por dez milhões. AGUIAR (2007, p.142) relata outras duas produções importantes, veiculadas pelo rádio, desse período:

\footnotetext{
Entre 1963 e 1968 redige o programa semanal Nossa Música... Nossa Alma... para a Rádio MEC, verdadeiro estudo sobre a nossa cultura musical, utilizando discos como exemplos ilustrativos. Em fevereiro de 1964, em 0 Assunto é a Música, feito em colaboração com o Centro de Estudos e Pesquisas Musicais, do Sindicato dos Músicos Profissionais do Estado da Guanabara, produz uma série de programas sobre cinema, verdadeiras aulas sobre a evolução da produção musical para esse meio (...).
}

Três outros fatores chamam a atenção sobre a carreira profissional de Guerra-Peixe durante o tempo em que trabalhou na Rádio Nacional do Rio de Janeiro. 0 primeiro foi a volta ao seu instrumento: o violino, após ter passado cerca de vinte anos sem tocar. Em 1963, Guerra-Peixe ingressou como violinista da Orquestra Sinfônica Nacional da Rádio MEC (Ministério da Educação e Cultura), na qual permaneceu por cinco anos até se aposentar da função de instrumentista, em 1968. Um segundo fator foi a aceitação do convite feito pelo compositor Heitor Alimonda para dar aulas de Harmonia nos Seminários de Música Pró-Arte: "ao que parece, Guerra-Peixe se entusiasmou com a nova frente de trabalho aberta pelo desenvolver natural de sua carreira de compositor" (FARIA JR., 1997, p.83). 0 terceiro ponto foi a retomada ao trabalho de composição, interrompido em 1960, tendo como última composição daquele ano a Sinfonia Brasilia $n^{\circ} 2$, para reiniciar no ano de 1966, com a composição do Ponteado para violão e, logo, em 1967, com a Sonata para piano $n^{\circ} 2.0$ retorno à composição coincide com uma ênfase ainda mais acentuada na simplificação da escrita: "reduz a dificuldade em benefício da praticidade de execução. Com isso, as peças ganharam extrema comunicabilidade" (MALAMUNT, 1999, p.51).

As últimas atividades que ocorrem em paralelo ao seu contrato com a Rádio Nacional, como relatado por AGUIAR (2007, p.144), foram: o trabalho de arranjador para a TV Tupi do Rio de Janeiro, do ano de 1966 até o final da década de 1970, e os arranjos escritos para o Festival Internacional da Canção de 1967.

\section{7 - Últimos trabalhos como arranjador}

Ao chegar aos 60 anos de idade, aposentado "por todos os lados" - "pelo INPS [Instituto Nacional de Previdência Social] há vinte anos, como compositor, músico; aposentado pela Orquestra Sinfônica Nacional [da Rádio MEC], que está nos quadros culturais da UFP, aposentado como professor universitário" (CAVALCANTI, 2007, p.123) - Guerra-Peixe, em entrevista ao Jornal do Brasil, em 10 de maio de 1974, fez um balanço de sua carreira profissional. 0 título da reportagem já aponta sua atitude - "Agora é tempo de recuperar o tempo perdido". Nessa reportagem o compositor declarou para o entrevistador Edino Krieger: "Passei 43 anos fazendo arranjinhos de música popular para sobreviver; só agora que me aposentei é que vou poder me dedicar à música que quero fazer. Não faço mais arranjos para discos, nem música para cinema nada dessas coisas". É claro que sua posição não permaneceu tão radical. A partir desse momento, de acordo com seu depoimento (1992a), sua tabela de preços para esse tipo de serviço passou a estar na média de quinze mil dólares pela produção de um disco com 12 faixas.

Apesar das frequentes solicitações dos canais de televisão para que escrevesse arranjos tirados de discos, trabalho que ele se recusava tenazmente a fazer, a partir de sua aposentadoria Guerra-Peixe não trabalhou mais como arranjador contratado de nenhuma emissora de rádio, canal de televisão ou gravadora.

Os últimos trabalhos de maior repercussão como arranjador foram: a realização do projeto de arranjos sinfônicos para songbooks, projeto organizado pelo publicitário

\begin{tabular}{|l|l|l|l|l|}
\hline Ano & Maestro & Salário & Função & Observação \\
\hline 1962 & Guerra-Peixe & $\operatorname{Cr} \$ 60.000,00$ & Arranjador e regente & \\
\hline
\end{tabular}

Ex. 1: tabela de renumeração e função de Guerra-Peixe na função de maestro da orquestra da Rádio nacional do Rio de janeiro. 
Marcus Pereira e gravado pelo selo Chantecler, presente na coleção intitulada A grande música do Brasil, uma série de três discos separados por compositores: Tom Jobim, Chico Buarque e Luiz Gonzaga, lançado no final da década de 1970. E os arranjos sinfônicos (solo orquestral) para as músicas do disco chamado Afro Sambas, de Baden Powell e Vinícius de Morais, lançado em 1966, para o qual também tinha feito os arranjos para a gravação do LP cantado. Segundo AGUIAR (2007, p.146), a execução de seus arranjos sinfônicos para os cantos afro-brasileiros de Baden e Vinícius aconteceu em 1992, no programa de televisão Os arranjadores transmitido pela TV Cultura de São Paulo, sendo, simultaneamente, sua última aparição na televisão e a última regência de uma orquestra sinfônica ${ }^{3}$. Como últimos trabalhos na área também incluem diversos arranjos escritos para músicas apresentadas nos festivais de música da televisão, como Ponteio e Upa neguinho de Edu Lobo, além da participação como júri em alguns destes festivais. 0 último arranjo feito na sua vida foi o arranjo de cordas para música Cinema novo, presente no LP Tropicália II, gravado pelo selo Polygram, de Caetano Veloso e Gilberto Gil, conforme AGUIAR (2007, p.146).

0 último prêmio como arranjador foi a troféu Pixinguinha - melhor orquestração, recebido no I Concurso de Música Natalina, promovido pela Secretaria de Turismo de Guanabara, em 1969.

As atividades pedagógicas como professor de música ajudam a entender seu envolvimento com a música popular, bem como seu interesse em passar o aprendizado advindo da longa experiência de arranjador para os seus alunos. É possível traçar um breve panorama do percurso de Guerra-Peixe no desempenho dessa função. De 1950 a 1952, deu aulas particulares no Recife. De 1954 a 1959, deu aulas, palestras, conferências e cursos em São Paulo. De 1961 a 1978, participou ativamente de alguns cursos no Rio de Janeiro: Seminário de Música Pró-Arte, de 1963 a 1970; criação da Escola Brasileira de Música Popular do Museu da Imagem e do Som, de 1968 a 1972; aulas no Centro de Estudos Musicais, de 1972 a 1980; e Oficina Musical de Guerra-Peixe ministradas na Escola de Música Villa Lobos - RJ, de 1981 a 1991. Atuou ainda como professor de Composição da Escola de Música da Universidade Federal de Minas Gerais - UFMG, de 1980 a 1989 e, após ser transferido, como professor da Universidade Federal do Rio de Janeiro, de 1989 a 1990.

Em meio a essa intensa atividade pedagógica, o que chama atenção era a sua intensa preocupação com a formação dos músicos brasileiros. Muitas vezes, ao perceber o interesse de determinado aluno, aceitava dar aulas de graça por tempo indeterminado caso este não pudesse lhe pagar. Inclusive, foi iniciativa sua a criação da Escola Brasileira de Música Popular, "objetivando elevar o nível técnico dos que se dedicam à música popularesca (...)" (GUERRA-PEIXE, 1971, p.5).
Quando questionado sobre os profissionais que se dedicam à prática de arranjo para música popular, GUERRAPEIXE (1979, p.1-2) respondeu:

\begin{abstract}
0 problema dessa gente é que não quer estudar. Uma das únicas exceções que conheço é a do Geraldinho Vespar, que levou a sério o estudo. É um orquestrador consciente, sem dúvida. Muitos outros aprendem um bocadinho e vão adivinhando. Compram métodos estrangeiros e se limitam a aprender estilos alheios. Aliás, arranjador e maestro são apelidos. Virou falta de respeito profissional.
\end{abstract}

Tal declaração revela o interesse do compositor em formalizar o estudo da música popular com intenção de elevar o nivel técnico dos profissionais dessa área, bem como da própria música popular. Nesse sentido, um depoimento de um ex-aluno do curso de música popular de GuerraPeixe confirma essa sua vontade:

Outra coisa que me influenciou no longo contato com o professor foi a seriedade com que ele encarava a música e a profissão de músico. Apesar dele não falar clara e diretamente, eu sentia em suas atitudes que ele não aprovava um músico fazer concessões em sua carreira profissional quando essas concessões comprometessem a qualidade artística da música. Acredito que a minha concepção musical começou a tomar uma forma mais definida depois do meu envolvimento com o ensino e as ideias de Guerra-Peixe. A partir dessa fonte eu passei a encarar a profissão com mais seriedade e respeito (MAURO JR., 2007, p.199).

Além de Geraldo Vespar e Haroldo Mauro Júnior, nos cursos de Guerra-Peixe passaram nomes que tiveram expressiva atuação na música popular brasileira, como Chiquinho Morais, Capiba, Sivuca, Rildo Hora, Baden Powell, Formiga, Juca Chaves, Roberto Menescal, Jards Macalé, Nestor de Hollanda, Antônio Guerreiro, Randolf Miguel, Guilherme Bauer, Jorge Antunes, Portinho, Antônio Adolfo 4 e Moacyr Santos.

Guerra-Peixe faleceu no dia 26 de novembro de 1993. Segundo os pesquisadores FARIA JR. (1997, p.120) e NEPOMUCENO (2001, p.54), somente nas últimas composições - Rapsódia: Angustiante e Rapsodicamente, encomendada pelo Departamento de Cultura do Estado de São Paulo, em outubro de 1993; e no Trio (piano, violino e violoncelo), encomendado pela Associação Rio-Arte, incompleto por motivo de seu falecimento-, é que o compositor consentiu em usar elementos de "música popularesca" em suas composições, recurso que Radamés Gnattali utilizou sempre sem nunca precisar padecer para isso.

\section{8 - Conclusão}

0 levantamento da carreira de Guerra-Peixe como arranjador de orquestras de rádio traz elementos novos na compreensão da vida musical do compositor. É relevante o fato de que essa profissão foi a sua principal fonte de renda durante toda a sua vida, como ocorreu com outros compositores contemporâneos brasileiros. Tal estudo demonstra que importantes compositores eruditos brasileiros encontraram no campo de atuação profissional da música popular a renda que não conseguiam obter por meio apenas da música erudita. 


\section{Referências}

ASSIS, Ana Cláudia de. Compondo a "cor nacional": conciliações estéticas e culturais na música dodecafônica de César Guerra-Peixe. Per Musi. n.16. Belo Horizonte: UFMG, 2007. p.33-41

CABRAL, Sérgio. A MPB na era do Rádio. São Paulo: Ed. Moderna, 1990.

CASTRO, Ruy. Chega de saudade: A História e as histórias da Bossa Nova. Rio de Janeiro: Ed. Companhia das Letras, 1999. DELL' ORTO, Ângelo. Aspectos interpretativos da Sonata nº 2 de César Guerra-Peixe. 1998. Dissertação (Mestrado em Música) - Universidade Federal do Rio de Janeiro, Rio de Janeiro, 1998.

FARIA JR. Antonio. Emanuel Guerreiro. Guerra-Peixe: Sua Evolução Estilística à Luz das Teses Andreanas. 1997. Dissertação (Mestrado em Música)-Universidade Federal do Rio de Janeiro, 1997.

GUERRA-PEIXE, César. Melos e Harmonia Acústica. Princípios de composição musical. São Paulo: Irmãos Vitale, 1988. Para onde vai à música popular brasileira. Arrastão. Jornal de Arte, Rio de Janeiro, p. 4, ago. 1965. Depoimento. Série: Memória Arranjadores. FMIS de São Paulo, 1992

Depoimento. Compositores brasileiros. FMIS do Rio de Janeiro, 1992.

Estudos sobre música popular urbana. Minas Gerais: Ed. Da UFMG/PETROBRÁS Cultural, 2007.

LACERDA, Bruno Renato. Arranjos de Guerra-Peixe para a orquestra da Rádio nacional do Rio de Janeiro. 2009. Dissertação (Mestrado em Música)-Universidade Estadual Paulista, São Paulo, 2009.

MALAMUT, S. V. A flauta na música de câmara de Guerra-Peixe. 1999. Dissertação (Mestrado em Música)-Universidade Federal do Estado do Rio de Janeiro, Rio de Janeiro, 1999.

MARIZ, Vasco. Jornal correio da manhã. César Guerra-Peixe. 1952-53, p. 11-12.

MIGUEL, Randolf. A estilização do folclore na composição de Guerra-Peixe. 2006. Dissertação (Mestrado em Música)Universidade Federal do Estado do Rio de Janeiro, Rio de Janeiro, 2006.

NEPOMUCENO, Rosa. César Guerra-Peixe: A música sem fronteiras. Rio de Janeiro: FUNARTE, 2001.

ONOFRE, Cíntia Campolina. 0 Zoom nas trilhas de Vera Cruz - A trilha musical da companhia cinematográfica Vera Cruz. Dissertação (Mestrado em Música)-Universidade Estadual de Campinas, Campinas, 2005.

PEREIRA, Leandro Ribeiro. Rádio Nacional do Rio de Janeiro. A música popular brasileira e seus arranjadores (Década de 1930 a 1960). Dissertação (Mestrado em Música)-Universidade Federal do Estado do Rio de Janeiro, Rio de Janeiro, 2006.

SÉRIE DE MÚSICA BRASILEIRA. Guerra-Peixe. Rio de Janeiro: Centro Cultural Banco do Brasil, 7-28 nov. 1995.

SERRÃO, Ruth. Guerra-Peixe: um músico brasileiro. Rio de Janeiro: LUMIAR, 2007.

VIEIRA, Sonia. Maria. Características instrumentais na obra para piano de César Guerra Peixe. 1985. Dissertação (Mestrado em Música)-Universidade Federal do Rio de Janeiro, Rio de Janeiro, 1985.

\section{Notas}

1 Composto inicialmente para um programa de rádio este hino foi, depois de gravado, "oficialmente adotado nas escolas públicas da antiga Guanabara e outros Estados da Federação, em arranjos para duas ou três vozes. Este hino é também executado por bandas de música, inclusive nas paradas militares" (MIGUEL, 2006, p.24), como a de 7 de setembro entre outras solenidades, por exemplo, quando foi executado na inauguração do Estádio do Maracanã, em 16 de junho de 1950, segundo afirmou AGUIAR (2007, p.132).

2 Hermann Scherchen foi um profundo interessado na divulgação da música dodecafônica e foi por meio da execução de obras como o Noneto e Sinfonia n¹ (dodecafônica) de Guerra-Peixe que o maestro conheceu o compositor (ARAÚJ0, 2007, p.31).

3 As partituras, tanto dos arranjos sinfônicos instrumentais, como do disco Afro-Sambas, encontram-se em posse de sua sobrinha neta, Jane GuerraPeixe. Sem dúvida, esse material merece um estudo aprofundado que poderia resultar em uma ótima pesquisa, através da qual poderiam ser divulgados outros aspectos interessantes da escrita criativa desse compositor. A fita de vídeo com a execução da 'sinfonização' dos Afro-sambas deve estar em algum arquivo cultural de São Paulo.

4 Quando Radamés Gnattali foi questionado pelo produtor musical Antonio Adolfo sobre quem seria o professor ideal para dar continuação aos seus estudos musicais - contraponto, harmonia, composição - ele respondeu de imediato: "procura o Guerra, Guerra-Peixe. Ele é o cara. Não tenha dúvidas" (ADOLFO, 2007, p.189).

Bruno Renato Lacerda é Mestre em Música pela Universidade Estadual Paulista Júlio de Mesquita Filho - UNESP, maio de 2009, realizada com bolsa de estudos fornecida pela Coordenação de Aperfeiçoamento de Pessoal de Nivel Superior - CAPES, de abril de 2008 a maio de 2009. Arquivista da Orquestra Experimental de Repertório do Estado de São Paulo, julho de 2009 até o presente momento. Graduação em Composição e Regência pela Faculdade das Artes Alcântara Machado - FAAM -, dezembro de 2005. Prêmio Acadêmico obtido por ter estado entre os cinco melhores alunos da turma no ano de 2002, título atribuído pela instituição de ensino UniFMU - FIAM/FAAM. Monitor da disciplina Harmonia com a supervisão da Profa Mas. Marisa Ramires nos anos de 2003, 2004 e 2005, durante o bacharelado. Professor substituto do Prof. Mestre Ricardo Rizek, ministrando aulas de Composição Musical para a turma do $6^{\circ}$ semestre de bacharelado em Composição da faculdade FAAM, de fevereiro a junho de 2005. 